consolidation and electroconvulsive shock. Psychological Review, 1965, 72, 225-239.

LEWIS, D. J., \& MAHER, B. A. Electroconvulsive shock and inhibition: Some problems considered. Psychological Review, $1966,73,388-392$.

McGAUGH, J. L. Time dependent processes in memory storage. Science, 1966, 153 , 1351-1358.

McGAUGH, J. L., \& PETRINOVICH, L. F.
Neural consolidation and electroconvulsive shock re-examined. Psychological Review, 1966, 73, 382-387.

MASSOPUST, L. C., JR. Diencephalon of the rat. In D. E. Sheer (Ed.), Electrical stimulation of the brain. Austin: University of Texas Press, 1961. Pp. 182-202.

WASMAN, M., \& FLYNN, J. P. Directed attack behavior during hippocampal seizures. Archives of Neurology, 1966, 14, 408-414.

\section{Rat activity as a function of water deprivation and age}

\author{
JAMES R. FRAZIER* \\ Florida State University, Tallahassee, Fla. 32306
}

Four rats were water deprived for $24,48,72,96$, and $120 \mathrm{~h}$, beginning at ages 37,59 , and 81 days. Naive ( 37 days) Ss increased activity over baseline after $24 \mathrm{~h}$; deprivation-experienced $S s$ showed activity decrements after $24 \mathrm{~h}$. All Ss sharply decreased activity at $120 \mathrm{~h}$ at each age interval.

Several studies have reported rat activity in photoelectric cages as a function of water deprivation at a single age level (Finger, 1962; Grimsley, 1965). Using a $3 \frac{1}{2}-$-in-wide circular alley bisected by light beams, Grimsley (1965) found a trend toward daily activity increments under 0 , $24,48,72$, and $96 \mathrm{~h}$ of water deprivation for 90 - to 110-day-old rats. Finger (1962) measured daily activity of 40-day-old rats under 24 and $48 \mathrm{~h}$ of deprivation. Compared to baseline activity, he found median performance decrements to be $29.5 \%$ and $43.0 \%$, respectively, for 24 and $48 \mathrm{~h}$ of deprivation. The present study replicated certain aspects of Finger's study, but extended deprivation and age parameters.

\section{METHOD}

The Ss were four male rats from the Dublin laboratories maintained on an illumination cycle of $12 \mathrm{~h}$ light and $12 \mathrm{~h}$ dark, the former beginning at 7:30 a.m. The home cage served as the experimental apparatus. This wire-mesh cage was a replica of Finger's (1962) apparatus. The dimensions were 22 in. long $x 8$ in. high $x$ 8 in. wide, with both length and width bisected by a photocell beam. Interruption of the beam activated an external counter that recorded the responses. A food cup containing Purina Lab Chow was attached

*Author now at the Child Development Institute, University of North Carolina. Chapel Hill, N.C. 27514. to a side near the front, through which projected the water tube. Cages were housed under normal laboratory conditions, with the average temperature $75^{\circ} \mathrm{F}$ and relative humidity $45 \%$.

The Ss were weaned at approximately 20 days of age, and baseline measures began the 28 th day. Food and water were ad lib for a 9-day adaptation period until activity stabilized. Stability was determined by visual inspection of the data. During the last hour of each day's light cycle, Ss were weighed to the nearest

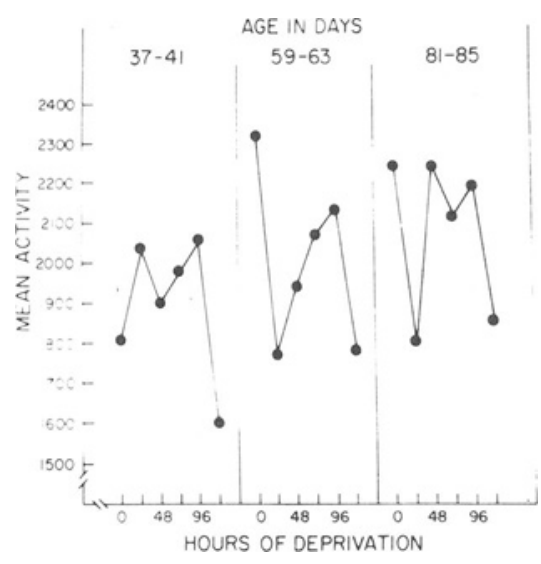

Fig. 1. Mean activity as a function of hours of water deprivation at three age levels. Each point represents total number of beam interruptions during a $23-\mathrm{h}$ period for four animals. gram, food and water intake was recorded to the nearest gram and milliliter for the previous $23 \mathrm{~h}$, and general maintenance was accomplished. Total daily activity was recorded from the counters as number of beam interruptions for that period.

When the Ss were 37 days of age, water bottles were removed from all Ss after the maintenance period and deprivation was continued for $120 \mathrm{~h}$ ( 5 days). No other change in conditions occurred and water was returned after the 5-day interval. Daily measures were taken of weight, food and water consumption, and activity, just as in adaptation. This procedure was recycled every 22 days, allowing 17 days between deprivation periods for $S s$ to recover weight losses and stabilize food and water intake. Thus each animal was deprived beginning at 37,59 , and 81 days of age.

\section{RESULTS}

Total number of beam interruptions during $23 \mathrm{~h}$ constituted the activity measure. Figure 1 represents mean number of beam interruptions associated with deprivation hours and age. From baseline, naive ( 37 days) Ss' activity increased across 4 days and dropped sharply on Day 5. After deprivation experience 59. and 81-day-old Ss decreased responding the first day, generally increased responding through Day 4 , and reduced activity on Day 5 .

\section{DISCUSSION}

Present data do not support previous findings of activity decrements for 40-day-old rats 24 and $48 \mathrm{~h}$ water deprived (Finger, 1962). However, Finger's Ss were $48 \mathrm{~h}$ food deprived, received a 10-day recovery period, then $48 \mathrm{~h}$ deprived. Perhaps these procedural differences are related to disparity in results.

If one compares data using $S s$ with deprivation experience, irrespective of kind of deprivation, similar trends between Finger's results and present data emerge. Finger's water-deprived Ss, following food deprivation and recovery, decreased total daily activity from baseline by $30 \%$ and $40 \%$, respectively, after 24 and $48 \mathrm{~h}$ of deprivation. Water deprivation experienced animals in this study, 59 days old, decreased total daily activity by $26 \%$ and $17 \%$, respectively, after 24 and $48 \mathrm{~h}$. Thus the trends suggest that experience with prior deprivation, at least in young animals, might be a factor to consider in any interpretation of water deprivation effects on measures of activity.

\section{REFERENCES}

FINGER, F. W. Activity under deprivation as a function of age. Joumal of Comparative \& Physiological Psychology, 1962, 55, 100-102. GRIMSLEY, D. L. Effects of water deprivation and injections of hypertonic saline on the activity of rats. Psychological Reports, 1965 , $16,1081-1085$. 